\title{
True Aneurysms of the Extracranial Carotid Artery : An Evaluation of Two "Giant Aneurysms" and the Current Literature
}

\author{
Gokalp Altun, M.D., Zerrin Pulathan, M.D., ${ }^{1}$ Dogus Hemsinli, M.D. ${ }^{2}$ \\ Department of Cardiovascular Surgery, Karadeniz Technical University, School of Medicine, Trabzon, Turkey \\ Department of Cardiovascular Surgery, Kanuni Training and Research Hospital, Trabzon, Turkey
}

True extracranial carotid artery aneurysms (ECCAs) are uncommon. Atherosclerosis is the most common etiological factor. Neck pain, a pulsatile mass and murmur at auscultation are the most common symptoms. ECCAs may exhibit severe clinical manifestations due to complications. Cases of rupture can be fatal. There is a risk of distal embolization and stroke in thrombosed cases. We discuss two cases of enlarged ECCA treated surgically in the light of the most recent literature.

Key Words : Carotid arteries · Aneursym · Surgical procedures, Operative.

\section{INTRODUCTION}

Although true extracranial carotid artery aneurysms (ECCAs) are uncommon, they may involve severe clinical presentations due to complications. Carotid artery aneurysms constitute less than $1 \%$ of all peripheral artery aneurysms. Aneurysms can be classified as true aneurysms and pseudoaneurysms. According to meta-analysis reports, the majority of carotid artery aneurysms are pseudoaneurysms ${ }^{9,10)}$. Arterial pseudoaneurysms are pulsatile, expandable masses, associated with swelling and pain. An encapsulated hematoma with pulsation which is located around arteries as well as related with the lumen of a ruptured vessel is defined as "pseudoaneurysm formation". Aneurysmal sac and increase in vessel size are occured due to arterial blood pressure; however, this dilatation is not consisted of every vessel wall layers. They most commonly develop secondary to trauma to blood vessel and less commonly after surgeries such as carotid repair. Atherosclerosis may lead to pseudoaneurysm formation through a process involving weakening of the vessel wall eventually causing ulceration. True aneurysms are the localized permanent enlargement of the artery diameter, with integrity of all vascular layers. True aneurysms constitute less than $10 \%$ of ECCAs. Some cases may be asymptomatic. The most common local symptoms and signs are a pulsatile mass, murmur at auscultation and neck pain. They may be life-threatening with serious clinical entities such as rupture and stroke $\mathrm{e}^{1-3,5,6)}$.

Atherosclerosis is the most common etiological factor espe-

- Received : April 7, 2017 •Revised : July 27, 2017 •Accepted : August 24, 2017

- Address for reprints : Gokalp Altun, M.D.

Department of Cardiovascular Surgery, Karadeniz Technical University, School of Medicine, Trabzon 61080, Turkey

Tel : +90-5323718692, Fax : +90-4622297157, E-mail : gokalpaltun@gmail.com

This is an Open Access article distributed under the terms of the Creative Commons Attribution Non-Commercial License (http://creativecommons.org/licenses/by-nc/4.0) which permits unrestricted non-commercial use, distribution, and reproduction in any medium, provided the original work is properly cited. 
cially for true aneurysms. Other etiological causes include Ehler-Danlos syndrome, fibromuscular dysplasia, local infections in the neck region, previous radiotherapy to the neck region and surgical trauma ${ }^{2,3}$.

In this paper, we present two cases of true ECCAs with the chief complaints pulsatile mass and neck pain. We treated these cases with open surgical procedures. The aim of this study is to discuss these cases in light of recent literature information.

\section{CASE REPORT}

\section{Case 1}

A 55-year-old woman presented to our clinic due to mass and pain in the right side of the neck. Physical examination revealed that the mass was pulsatile. A $3 \times 3.5 \mathrm{~cm}$ aneurysm beginning after the bifurcation of the right internal carotid artery (ICA) was determined at Doppler ultrasonography (USG). No thrombus was observed inside the sac. At computerized tomography (CT) angiography, saccular aneurysm was seen to begin $3 \mathrm{~cm}$ after the bifurcation, while the left main carotid artery and its branches and cerebral circulation were normal. The ICA was anastomosed end-to-end by resecting the aneurysmatic sac (Fig. 1). The patient was discharged on the 4th day postoperatively with no complications at follow-up. Histopathological examination of a surgical specimen identified an

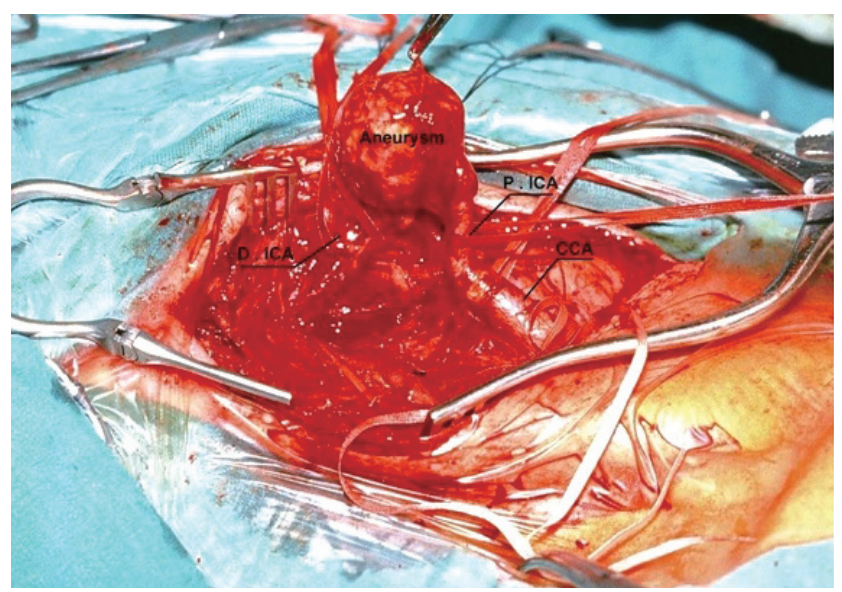

Fig. 1. Intraoperative image of case 1 . A $3 \times 3.5 \mathrm{~cm}$ aneurysm beginning after the bifurcation of the right internal carotid artery. The distance between the aneurysm sac and bifurcation was about $3 \mathrm{~cm}$. D.ICA : distal part of internal carotid artery, P.ICA : proximal part of internal carotid artery, CCA : common carotid artery. atherosclerotic aneurysm.

\section{Case 2}

A 68-year-old woman presented to our clinic due to a mass causing pain on the right side of her neck. Physical examination revealed that the mass was pulsatile. Neck movement maneuvers confirmed that the actual cause of pain was the mass and related excessive muscle tension or dilatation of the artery. Doppler USG revealed a $4 \times 4 \mathrm{~cm}$ aneurysm beginning $2 \mathrm{~cm}$ after the bifurcation of the ICA. At CT angiography, the distal ICA passed behind the saccular aneurysm, the sac was located in a high position, and the left main carotid artery and its branches and cerebral circulation were normal (Figs. 2 and 3). The aneurysm sac was observed to be attached to the hypoglossus nerve at surgery. The sac was excised with careful dissection. The freed ends were anastomosed in such a way as not to cause stricture. The patient was discharged on the 5th day postoperatively with no complications at follow-up. Histopathological examination of a surgical specimen identified an atherosclerotic aneurysm (Fig. 4).

The contralateral carotid artery systems were within normal limits in both cases before operations. Surgeries were performed under general anesthesia. Incisions of sufficient length were made medially to the sternocleidomastoid muscle. Re-

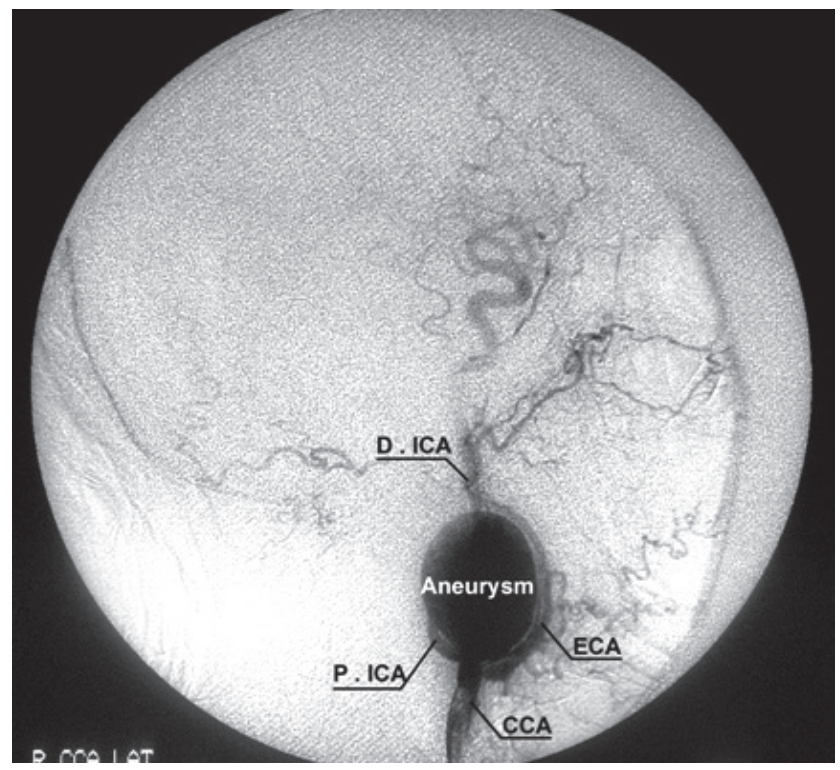

Fig. 2. Digital subtraction angiography image from case 2 . The elongation with kingking in internal carotid artery was remarkable. The external carotid artery (ECA) was also pushed by the aneurysm sac. D.ICA : distal part of internal carotid artery, P.ICA : proximal part of internal carotid artery, CCA : common carotid artery, R : right, LAT : lateral. 


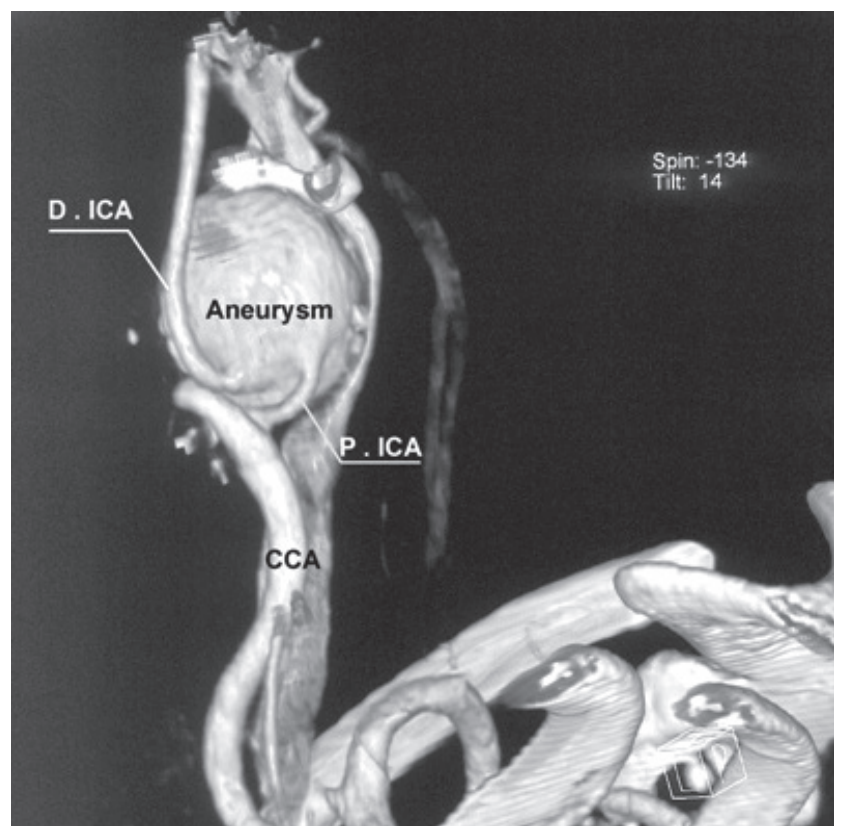

Fig. 3. Three-dimensional computerized tomography angiography image from case 2 . Elongation and kinking are notable in the distal and proximal parts of the internal carotid artery. D.ICA : distal part of internal carotid artery, P.ICA : proximal part of internal carotid artery, CCA : common carotid artery.

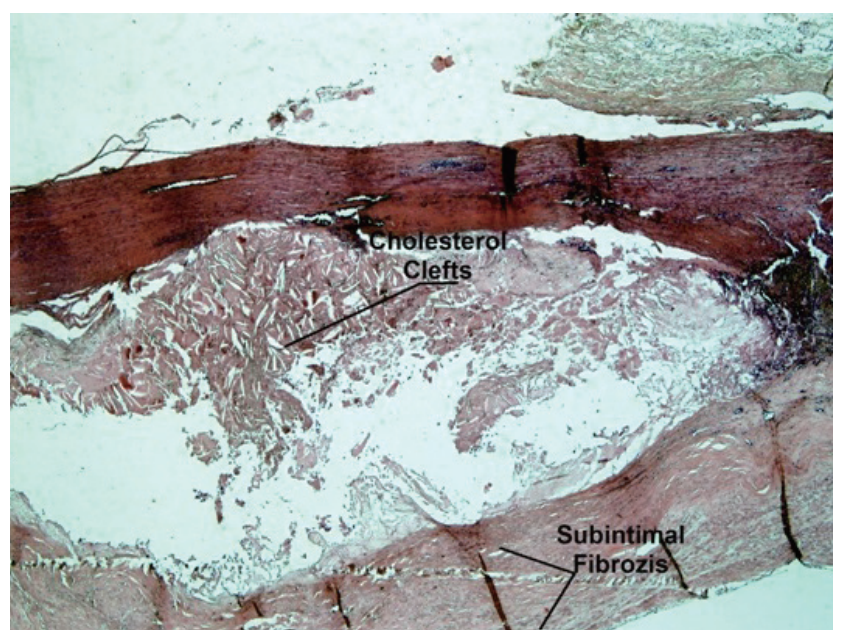

Fig. 4. Atherosclerotic changes in the wall of dilate vessel segment : subintimal fibrosis and cholesterol clefts (Periodic acid-Shiff stain, $\times 100$ high power field).

gional cerebral oxygen saturation and cerebral circulation were monitored in order to evaluate cerebral tissue oxygenation in both cases. Intraoperative, the stumpf pressures of distal ICAs were within the normal limits. End-to-end anastomoses were performed by using $6 / 0$ prolene continuing sutures. No shunt was used during anastomoses. Cross clamp time was $13 \mathrm{~min}-$ utes in case 1 and 17 minutes in case 2, respectively. No complications or neurological sequelae were observed in the postoperative period or at clinical follow-ups.

\section{DISCUSSION}

The definition of ECCAs in the literature is unclear. This is because dilatation of the carotid bulbus is sometimes evaluated as physiological. In other words, there is a fine line between the definitions of dilatation and aneurysm. The classic definition of aneurysm is an increase of less than 50\% in the normal arterial diameter. Bulbus dilatation, however, is regarded as a greater than $200 \%$ increase in the diameter of the ICA or a greater than $150 \%$ increase in that of the common carotid artery ${ }^{5}$.

The most common presentation is a neck mass. It may be painful. The pain is more often functional and mostly due to the tension of the dilated carotid arteries. It also triggers reflex muscle spasm as a result of excessive stress in the surrounding muscles. Inflammation in the carotid sheath can be another cause of pain. Neurological events such as stroke or transient ischemic attack caused by embolisms deriving from thrombus in the aneurysm may represent the first clinical findings. Dysphagia, voice restriction, earache extending to the neck, Horner's syndrome and, rarely, bleeding in association with sac rupture may be seen due to compression of neighboring tissues ${ }^{7-9)}$.

The incidence of true ECCAs is generally described as less than $1 \%$ in series involving the entire carotid entry ${ }^{4-11}$. Majority of ECCAs course silently. Manifestation of neurological symptoms, increase in size of the mass and cranial nerve dysfunction are common cause of seek for medical attention and treatment. The morphological classification of ECCAs is divided into five types, depending on the location of the aneurysm ${ }^{1)}$. The surgical options vary depending on this classification. In type 1 , the aneurysm is distal to the ICA. In type 2 it begins from the proximal ICA and extends toward the distal. In type 3 , the aneurysm is in the carotid bifurcation. In type 4, it is located in the ICA and common carotid artery (CCA) as a long segment. In type 5 , it is localized in the CCA. In the light of this classification, surgical options of aneurysmectomy+end-to-end anastomosis are generally applied in type 1 , aneurysmectomy+ autologous vein or Dacron-graft interposition in type 2 , aneurysmorrhaphy or patch plasty or aneurysmectomy+graft interposition in type 3 , aneurysmectomy+autologous vein inter- 
position+external carotid artery re-anastomosis in type 4 and aneurysmectomy+graft interposition in type $5^{1)}$. Both our cases were type 1 and both were treated with aneurysmectomy+endto-end anastomosis. Our cases may also be described as 'giant' in terms of their size and location.

Alternative treatments for ECCA have been reported with endovascular techniques in some recent publications. Considering the limited success rate of conventional methods (open surgery) for the treatment of ECCA it is obvious that there is a need for more effective techniques to be implemented. For this regard endovascular techniques offer opitimistic alternative especially in cases with previous neck surgery, hostile neck conditions casued by interventions such as radiotherapy. Endovascular intervention was performed in $12.8 \%$ of cases in Mayo Clinic's series. All of these cases were pseudoaneurysms, but not true aneurysms ${ }^{6}$. Main factors affecting the choice between open surgery and endovascular intervention are aneurysm type and localization ${ }^{9)}$. Due to the idea of pseudoaneurysms as self-limiting, endovascular intervention may be an alternative treatment for this type of aneurysms ${ }^{6,10)}$. True ECCAs cases require endovascular instrument with bigger diameter and length. Endovascular interventions may also cause aneurysm degeneration due to regrowth or disease progression. Late complication, stroke and stent graft migration rates are increased in these patients ${ }^{8}$. In addition, endovascular treatment can not relieve compression-related symptoms because existing aneurysmal sac still cause mass effect. Long-term results of endovascular intervention in these cases are still insufficient ${ }^{10)}$. For these reasons, endovascular interventions for patients with ECCAs may not be best treatment option. However, although this is a promising development, it has not yet become an alternative to open surgery ${ }^{12,13)}$. Surgical repair levels of $94 \%$, endovascular treatment at 5\% and hybrid treatment options at $1 \%$ have been reported in invasive therapies in case series ${ }^{12}$. According to a recent review conservative management of ECCAs results in $4.67 \%$ mortality and $6.67 \%$ stroke and invasive treatment reduced the rate of mortality to $1.91 \%$ and $5.16 \%$ stroke development. These levels suggest that surgery is superior to conservative treatment. Cranial nerve injury at a level of $11.8 \%$ has also been observed during open surgery therapy $^{12)}$. Ligation is also a traditional therapeutic method in selected cases.

\section{CONCLUSION}

ECCAs are uncommon, but nevertheless represent a serious clinical condition in the light of potential complications. Open surgery is still the preferred therapeutic option.

\section{CONFLICTS OF INTEREST}

The authors have no financial conflicts of interest.

\section{INFORMED CONSENT}

Informed consent was obtained from all individual participants included in this study.

\section{References}

1. Attigah N, Külkens S, Zausig N, Hansmann J, Ringleb P, Hakimi M, et al. : Surgical therapy of extracranial carotid artery aneurysms: long-term results over a 24-year period. Eur J Vasc Endovasc Surg 37 : 127-133, 2009

2. Cinar $B$, Fazlioğullari $\mathrm{O}$, Goksel 0 : True aneurysm of extracranial internal carotid artery in a 10-year-old. Eur J Vasc Endovasc Surg 32 : 386388, 2006

3. DeFatta RJ, Verret DJ, Bauer P : Extracranial internal carotid artery pseudoaneurysm. Int J Pediatr Otorhinolaryngol 69 : 1135-1139, 2005

4. Donas KP, Schulte S, Pitoulias GA, Siebertz S, Horsch S: Surgical outcome of degenerative versus postreconstructive extracranial carotid artery aneurysms. J Vasc Surg 49 : 93-98, 2009

5. Faggioli GL, Freyrie A, Stella A, Pedrini L, Gargiulo M, Tarantini S, et al. : Extracranial internal carotid artery aneurysms: results of a surgical series with long-term follow-up. J Vasc Surg 23 : 587-594, 1996

6. Fankhauser GT, Stone WM, Fowl RJ, O'Donnell ME, Bower TC, Meyer FB, et al. : Surgical and medical management of extracranial carotid artery aneurysms. J Vasc Surg 61 : 389-393, 2015

7. Garg K, Rockman CB, Lee V, Maldonado TS, Jacobowitz GR, Adelman $M A$, et al. : Presentation and management of carotid artery aneurysms and pseudoaneurysms. J Vasc Surg 55 : 1618-1622, 2012

8. Li Z, Chang G, Yao C, Guo L, Liu Y, Wang M, et al. : Endovascular stenting of extracranial carotid artery aneurysm: a systematic review. Eur J Vasc Endovasc Surg 42 : 419-426, 2011

9. Longo GM, Kibbe MR : Aneurysms of the carotid artery. Semin Vasc Surg $18: 178-183,2005$

10. Ni L, Pu Z, Zeng R, Zhang R, Zheng YH, Ye W, et al. : Endovascular stenting for extracranial carotid artery aneurysms: experiences and mid-term results. Medicine (Baltimore) 95 : e5442, 2016 
11. Rivera-Chavarría IJ, Alvarado-Marín JC : Endovascular repair for an extracranial internal carotid aneurysm with cervical access: a case report. Int J Surg Case Rep 19 : 14-16, 2016

12. Szopinski P, Ciostek P, Kielar M, Myrcha P, Pleban E, Noszczyk W : A series of 15 patients with extracranial carotid artery aneurysms: surgical and endovascular treatment. Eur J Vasc Endovasc Surg 29 : 256-261, 2005

13. Welleweerd JC, den Ruijter HM, Nelissen BG, Bots ML, Kappelle LJ, Rinkel GJ, et al. : Management of extracranial carotid artery aneurysm. Eur J Vasc Endovasc Surg 50 : 141-147, 2015 